\title{
COMMUTATIVITY OF PRIME RINGS WITH SYMMETRIC BIDERIVATIONS
}

\author{
B. RAMOoRThy REDDY \\ Research Scholar \\ Department of Mathematics, S.V. University \\ Tirupati-517502, Andhra Pradesh, India \\ e-mail: ramoorthymaths@gmail.com \\ AND \\ C. Jaya Subba Reddy \\ Assistant professor \\ Department of Mathematics, S.V. University \\ Tirupati-517502, Andhra Pradesh, India \\ e-mail: cjsreddysvu@gmail.com
}

\begin{abstract}
The present paper shows some results on the commutativity of $R$ : Let $R$ be a prime ring and for any nonzero ideal $I$ of $R$, if $R$ admits a biderivation $B$ such that it satisfies any one of the following properties (i) $B([x, y], z)=$ $[x, y]$, (ii) $B([x, y], m)+[x, y]=0$, (iii) $B(x o y, z)=x o y$, (iv) $B(x o y, z)+$ $x o y=0,(\mathrm{v}) B(x, y) o B(y, z)=0, \quad(\mathrm{vi}) B(x, y) o B(y, z)=x o z$, (vii) $B(x, y) o B(y, z)+x o y=0$, for all $x, y, z \in R$, then $R$ is a commutative ring.
\end{abstract}

Keywords: prime ring, biderivation, commutativity and ideals.

2010 Mathematics Subject Classification: 16W25, 16N60, 16 U80.

\section{REFERENCES}

[1] M. Ashraf and N.U. Rehman, On commutativity of rings with derivations, Result. Math. 42 (2002) 03-08.

[2] M. Ashraf and N.U. Rehman, On derivation and commutativity in prime rings, East-West J. Math. 3 (2001) 87-91.

[3] M. Atteya and D. Resan, Commuting derivations of semiprime rings, Int. J. Math. Sci. 6 (2011) 1151-1158. 
[4] H.E. Bell and M.N. Daif, On derivations and commutativity in prime rings, Acta Math. Hungar. 66 (1995) 337-343.

[5] H.E. Bell and W.S. Martindale, Centralizing mappings of semiprime rings, Canad. Math. Bull. 30 (1987) 92-101.

[6] I.N. Herstein, A note on derivations, Canad. Math. Bull. 21 (1978) 369-370. doi:10.4153/CMB-1978-065-x

[7] T.K. Lee, Derivations and centralizing mappings in prime rings, Taiwanese. J. Math. 1 (1997) 333-342.

[8] G. Maksa, On the trace of symmetric biderivations, C.R. Math. Rep. Sci. Canada 9 (1987) 302-307.

[9] J.H. Mayne, Centralizing mappings of prime rings, Canad. Math. Bull. 27 (1984) $122-126$ doi:10.4153/CMB-1984-018-2

[10] E.C. Posner, Derivations in prime ring, Proc. Amer. Math. Soc. 8 (1957) 1093-1100.

[11] J. Vukman, Symmetric biderivations on prime and semi prime rings, Aequationes. Math. 38 (1989) 245-254.

[12] J. Vukman, Two results concerning symmetric biderivations on prime rings, Aequationes. Math. 40 (1990) 181-189.

[13] M.S. Yenigul and N. Argac, Ideals and symmetric biderivations on prime and semiprime rings, Math. J. Okayama Univ. 35 (1993) 189-192.

Received 15 February 2018

Revised 27 August 2018

Accepted 1 September 2018 